Journal of Advanced Dielectrics

Vol. 1, No. 1 (2011) 41-52

(C) World Scientific Publishing Company

DOI: 10.1142/S2010135X11000057

\title{
APPROACHES FOR A RELIABLE COMPOSITIONAL ANALYSIS OF ALKALINE-BASED LEAD-FREE PEROVSKITE CERAMICS USING MICROANALYTICAL METHODS
}

\author{
ANDREJA BENČAN ${ }^{*, \uparrow}$, ELENA TCHERNYCHOVA ${ }^{\dagger, \ddagger}, \|$, SAŠO ŠTURM ${ }^{\S, * *}$,

 \\ *Electronic Ceramics Department, Jozef Stefan Institute \\ Jamova ulica 39, Ljubljana, 1000, Slovenia \\ ${ }^{\dagger}$ Center of Excellence SPACE-SI, Aškerčeva cesta 12 \\ Ljubljana, 1000, Slovenia \\ ${ }^{\ddagger}$ Center of Excellence NAMASTE \\ Jamova ulica 39, Ljubljana, 1000, Slovenia \\ $\S_{\text {Department of Nanostructured Materials }}$ \\ Jozef Stefan Institute, Jamova ulica 39 \\ Ljubljana, 1000, Slovenia \\ 『andreja.bencan@ijs.si \\ "lelena.tchernychova@ijs.si \\ **saso.sturm@ijs.si \\ †'zoran.samardzija@ijs.si \\ ¥†arbara.malic@ijs.si \\ §§marija.kosec@ijs.si
}

Received 29 September 2010

Revised 15 November 2010

\begin{abstract}
The article describes the approaches for a reliable, quantitative compositional analysis of lead-free perovskite ceramics in powder and bulk forms that contain volatile alkaline compounds. The combination of scanning electron microscopy (SEM) and transmission electron microcopy (TEM) with electron-probe analytical techniques, such as energy-dispersive X-ray spectroscopy (EDS), wavelength-dispersive X-ray spectroscopy (WDS) and electron-energy-loss spectroscopy (EELS) makes it possible to determine the true chemical composition, from precursor powders to synthesized ceramics or single crystals. The microscale (SEM) and nanoscale (TEM) analytical methods also give an insight into the local variations of the chemical composition.
\end{abstract}

Keywords: $(\mathrm{K}, \mathrm{Na}) \mathrm{NbO}_{3} ; \mathrm{KTaO}_{3}$; EDS; WDS; EELS.

\footnotetext{
${ }^{\mathbb{T}}$ Corresponding author.
} 


\section{Introduction}

The discovery that the texturing of $(\mathrm{K}, \mathrm{Na}, \mathrm{Li})(\mathrm{Nb}$, $\mathrm{Ta}, \mathrm{Sb}) \mathrm{O}_{3}$ ceramics results in an enhancement of the piezoelectric properties as high as the values of lead zirconate titanate solid solutions ${ }^{1}$ has advanced the investigations of lead-free piezoceramics in the past decade. A significant breakthrough has been achieved in the synthesis, sintering and characterization in the field of lead-free materials ${ }^{2}$ and, especially, in alkaline-based piezoceramics ${ }^{3-5}$ in recent years. However, the problems of the compositional fluctuations and, consequently, the poor reproducibility of final functional properties are still on the priority research list for many investigators.

One of the examples where caution should be exercised during the processing is the use of solid-state synthesis, with an attempt to obtain compositionally homogeneous, alkaline-niobateand alkaline-tantalate-based ceramics. The strongly hygroscopic nature of alkaline carbonates, especially potassium carbonate, the different diffusion rates of the involved ionic species during the annealing, and the high sublimation rates of the alkaline species at high temperatures are common problems with these materials, which are known to give rise to deviations from stoichiometry. ${ }^{6-14}$ The resulting compositional inhomogeneities as well as the addition of dopants inevitably contribute to changes in the functional properties of alkaline-based ceramics. ${ }^{6,15-20}$

To be able to understand the composition-property relationships of these materials, their chemical composition, from the precursor powders to the synthesized ceramics or single crystals, has to be accurately determined. This raises the need for a reliable, spatially-resolved compositional analysis, which should be applied at every processing stage.

In the literature, relatively little attention has been paid to any detailed chemical composition analysis of these materials. One of the most commonly employed, nondestructive methods for exploring alkaline-based perovskite ceramics is X-ray diffraction (XRD) analysis. ${ }^{13,21-23}$ Apart from a crystal-structure-related analysis, the XRD data gives information about the bulk phase composition. The method allows a determination of the percentage of crystalline material versus amorphous; however, the amorphous phases cannot be identified. Additionally, fractions of the minor phases below $\sim 1-3$ vol\%, depending on the XRD configuration, cannot be detected. In cases where the complete quantitative elemental compositions of both powder and bulk ceramic materials need to be determined down to ppm concentrations, an Inductively Coupled Plasma (ICP) analysis can be performed. ${ }^{8,24-27}$ Another method in general use, which in addition to a visualization of the microstructure makes it possible to obtain compositional information from a localized area of the bulk sample, is electron-probe microanalysis (EPMA) within a scanning electron microscope (SEM). With SEMEPMA techniques, i.e., energy-dispersive X-ray spectroscopy (EDS) and wavelength-dispersive $\mathrm{X}$-ray spectroscopy (WDS), it is possible to gain the compositional information with a micrometerscale resolution and with typical detection limits of $\approx 0.1 \mathrm{wt} \%$ and $\approx 0.01 \mathrm{wt} \%$, respectively. ${ }^{28}$ Further improvements to the spatial resolution in the structural and compositional analyses can be achieved with transmission electron microscopy (TEM) techniques. Although the detection limits of TEM-EDS are the same as those in SEM-EDS, the analysis can be performed with a spatial resolution in the nanometer range. An atomically resolved chemical sensitivity can be achieved by using the electron-energy-loss spectroscopy (EELS) technique, which apart from the compositional determination enables probing of the bonding and valence changes in the material. ${ }^{29}$

In this review the approaches for a reliable compositional evaluation of alkaline-based, lead-free perovskite ceramics is addressed. Various members of the complex $(\mathrm{K}, \mathrm{Na}, \mathrm{Li})(\mathrm{Nb}, \mathrm{Ta}, \mathrm{Sb}) \mathrm{O}_{3}$ solid solution, such as $\mathrm{K}_{0.5} \mathrm{Na}_{0.5} \mathrm{NbO}_{3}(\mathrm{KNN}),\left(\mathrm{K}_{0.485} \mathrm{Na}_{0.485} \mathrm{Li}_{0.03}\right)$ $\left(\mathrm{Nb}_{0.8} \mathrm{Ta}_{0.2}\right) \mathrm{O}_{3}$ (KNLNT) and $\mathrm{KTaO}_{3}$, are described in examples of compositional evaluations using the above-introduced microanalytical techniques.

\section{Determination of the Chemical Composition by Means of SEM-EPMA}

Apart from imaging the morphology of powders, SEM imaging techniques are commonly used to investigate the microstructure of polished and/or etched surfaces of alkaline-based ceramics, since the densification behavior and, consequently, the microstructure are extremely sensitive to the overall composition and local deviations from the stoichiometry. ${ }^{10,11,20,30}$ Analytical SEM-EPMA techniques such as EDS and WDS give an opportunity to study 
the chemical composition of flat, polished bulk samples in a localized sample area in the micrometer range. Besides polishing and conductive carboncoating, the samples for SEM-EPMA do not undergo any chemical or heat treatment, which makes it possible to preserve the pristine composition.

One of the important issues in SEM-EPMA is the spatial analytical resolution. It is primarily defined by the electron interaction volume and depends on the sample's composition and the applied acceleration voltage. Although imaging with a modern SEM equipped with a field-emission gun (FEG) can achieve a resolution of about $1 \mathrm{~nm}$, the size of the analytical volume for compositional EPMA is much bigger. It is defined by the electron interaction volume which, consequently, defines the depth of the X-ray generation in the material. The electron interaction volume for various materials and different beam energies can be calculated prior to the experimental measurements. Such calculations can be performed using Monte Carlo simulation programs for electron scattering in solids, such as the CASINO program. ${ }^{31}$ This is a useful tool for the simulation, prediction and selection of the analytical conditions for the investigated material. Table 1 summarizes the ranges, i.e., the maximum interaction depths of the electrons calculated for $(\mathrm{K}, \mathrm{Na}) \mathrm{NbO}_{3}, \mathrm{KNbO}_{3}, \mathrm{NaNbO}_{3}$ and $\mathrm{KTaO}_{3}$ bulk ceramics for 6-, 10-, 15- and $20-\mathrm{keV}$ beam energies. Examples of visualized electron trajectories for 6 and $20 \mathrm{keV}$ are shown in Fig. 1. The interaction depth can be used as a rough estimate for the diameter of the excitation volume in the material.
Table 1. Electron-interaction depth (range) for different acceleration voltages (HT) for $\left(\mathrm{K}_{0.5} \mathrm{Na}_{0.5}\right) \mathrm{NbO}_{3}(\mathrm{KNN}), \mathrm{KNbO}_{3}$ $(\mathrm{KN}), \mathrm{NaNbO}_{3}(\mathrm{NN})$ and $\mathrm{KTaO}_{3}$ (KT) bulk ceramics, calculated using Monte Carlo (CASINO) simulations. ${ }^{31}$ The values are given with $\mathrm{a} \pm 0.05 \mu \mathrm{m}$ precision.

\begin{tabular}{rcccc}
\hline \multirow{2}{*}{$\begin{array}{l}\text { HT } \\
(\mathrm{kV})\end{array}$} & KNN & KN & NN & KT \\
\cline { 2 - 5 } & 0.75 & 0.73 & 0.59 & 0.65 \\
6 & 1.85 & 1.71 & 1.38 & 1.32 \\
10 & 3.80 & 3.25 & 2.75 & 2.50 \\
15 & 6.10 & 5.25 & 4.40 & 4.02 \\
20 & & & & \\
\hline
\end{tabular}

Here, the value of $6 \mathrm{keV}$ was chosen as the lowest beam energy that is still high enough for an adequate excitation of the $K-K \alpha$-line (at $3.313 \mathrm{keV}$ ). At lower beam energies this line cannot be excited properly and the quantification might become erroneous. It can be seen from the Table 1 that the interaction volume is in the micrometer range and rises almost linearly with the increasing acceleration voltage in all the considered ceramic materials. This means that caution should be taken when interpreting the data from the ceramics with a small grain size and in the presence of pores and secondary phases.

Generally, the quantification of EDS and WDS spectral data is based on measurements of the $\mathrm{X}$-ray intensities of the elements present in the sample with an unknown composition $\left(I_{s}\right)$ and the corresponding elemental intensities $\left(I_{\text {std }}\right)$ measured on reference materials/standards with known

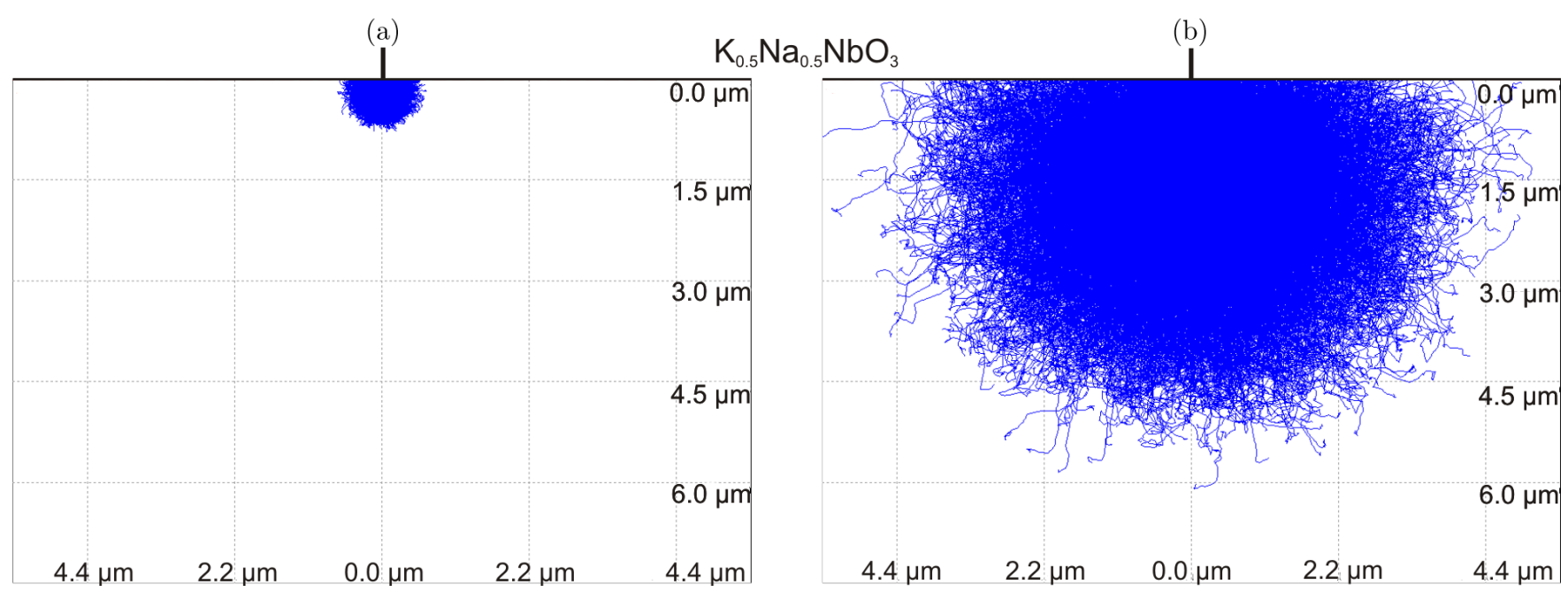

Fig. 1. Monte Carlo (CASINO) simulations ${ }^{31}$ of the electron trajectories give an illustration of the interaction volume in a bulk $\mathrm{K}_{0.5} \mathrm{Na}_{0.5} \mathrm{NbO}_{3}$ sample. Simulations were performed for $3 \cdot 10^{3}$ electrons with a primary beam energy of (a) $6 \mathrm{keV}$ and (b) $20 \mathrm{keV}$. 
compositions. It is necessary that the measurements on the unknown material and the standard(s) are performed under the same analytical conditions (beam energy, beam current and X-ray take-off angle). The obtained $I_{s} / I_{\text {std }}$ ratio for each analyzed element is referred to as a $k$-ratio. In order to obtain quantitative data for the elemental concentrations (in mass fractions or $\mathrm{wt} \%$ ) the values for all the elemental $k$-ratios have to be processed through the dedicated matrix correction programs that calculate the atomic number correction $(Z)$, the absorption correction $(A)$ and the fluorescence correction $(F)$, which are described in detail elsewhere. ${ }^{28}$ In commercial programs for quantitative EDS and/or WDS analysis, such matrix corrections are included as "ZAF" and/or "PhiRoZ" $(\Phi(\rho z))$ programs. PhiRoZ is a newer approach, which actually calculates the same $Z, A$ and $F$ corrections, but in a different way compared to the ZAF correction. Due to more reliable correction calculations the newest PhiRoZ methods are also more accurate and have almost completely replaced the use of the conventional ZAF method in the latest versions of commercial software.

Nowadays, all commercial EDS analytical systems have their own standards spectra database that is acquired and recorded for the dedicated SEM-EDS instrument at the factory and then included in the software for the quantization. Such a database, usually called a "virtual standards database" or a "stored reference library", can then be used for a theoretical calculation of the standard intensities for different elemental spectral lines $(K \alpha$, $L \alpha, M \alpha)$ and, consequently, can be employed for a so-called standardless EDS quantitative analysis. This standardless approach is frequently used for its convenience and the speed of the analysis; however, one has to be aware of the fact that it can lead to erroneous results, especially in the case of minor elemental concentrations, light-element analysis and EDS peak overlaps. Thus, to improve the accuracy of an EDS quantitative analysis the use of userdefined standards is preferred and recommended.

In contrast to the widely used EDS, ${ }^{11,25,32,33}$ a WDS analysis is less often used since it is a dedicated EPMA technique that is more time consuming. ${ }^{34,35}$ The higher beam currents usually applied in a WDS analysis can also affect the crystal structure and the chemical composition, especially when materials with volatile/migrating compounds are analyzed. A WDS spectrometer has a factor-of-10 better energy resolution than an EDS spectrometer, high peak-to-background ratios and a high count-rate capability. A properly optimized WDS procedure makes it possible to quantify minor and trace elements with a high degree of confidence and accuracy. Using this technique, light elements from Be can be analyzed and the separation of the peaks that overlap in an EDS spectra can be easily achieved. ${ }^{28}$ The choice of standard materials for the WDS method is very important and has to be carefully considered.

The complexity of the compositional characterization of alkali-based ceramics using electronmicroscopy analytical techniques arises from the presence of volatile compounds. The electron beam can give rise to various irradiation-induced effects, such as a migration of the alkaline ions and their sublimation. Therefore, in alkali-based ceramics, caution has to be taken, even at rather low, $5-20 \mathrm{kV}$, accelerating voltages in the SEM instrument. The best approach for both EDS and WDS is to probe the material for compositional stability at the desired working conditions. The early work of Samardžija et al..$^{34}$ shows a comprehensive study of such stability tests, performed for $\mathrm{NaNbO}_{3}$ and $\mathrm{KNbO}_{3}$ single crystals using SEM-EPMA. There, the stability of the samples was tested with WDS under $10-, 15-$ and $20-\mathrm{kV}$ accelerating voltages and 20-, 50- and 100-nA beam currents, applied for every voltage. The samples were irradiated at one spot for $100 \mathrm{~s}$ and counts for the selected line of each element were documented every $20 \mathrm{~s}$. A constant linear increase of the cumulative counts with the irradiation time for all the investigated elements, i.e., for $\mathrm{Na}, \mathrm{K}, \mathrm{Nb}$ and $\mathrm{O}$, demonstrated that both $\mathrm{NaNbO}_{3}$ and $\mathrm{KNbO}_{3}$ single crystals were stable under the electron beam for at least a $100 \mathrm{~s}$ acquisition time, even under severe conditions of $20 \mathrm{keV}$ and $100 \mathrm{nA}$. This confirmed that the alkali ions $\mathrm{Na}$ and $\mathrm{K}$ are stable in the perovskite $\mathrm{NaNbO}_{3}$ and $\mathrm{KNbO}_{3}$ crystal structures and do not migrate upon heating due to electron-beam irradiation during SEM-EDS or SEM-WDS microanalysis.

A comparison of both SEM-EDS and SEM-WDS techniques that were used for a quantitative compositional analysis of alkali-based ceramics, i.e., KNN, was performed by Samardzija et al. ${ }^{34}$ Two main problems were encountered, i.e., the choice of a more reliable method and the choice of the appropriate standards needed to be taken into consideration. The authors showed that a standardless, 
quantitative EDS analysis of polycrystalline KNN gave erroneous elemental compositions. In contrast to that, the quantitative WDS analysis gave excellent results that fitted well with the nominal composition of the perovskite $\mathrm{K}_{0.5} \mathrm{Na}_{0.5} \mathrm{NbO}_{3}$. Additionally, the authors discussed the problems of standards that are conventionally employed for the SEM-EPMA of potassium and sodium. Glasses containing $\mathrm{Na}$ and/or $\mathrm{K}$ or natural minerals with $\mathrm{Na}$ and/or $\mathrm{K}$ (albite, orthoclase), which are normally used as standards in both SEM-WDS and standardless SEM-EDS, are not reliable enough due to the appearance of compositional variations and the well-known beam-induced alkali migration $^{36}$ within a single specimen. Additionally, the alkali content in these minerals is rather low, which affects the precision of the analysis. Instead, the use of reliable, homogeneous and stable standard materials such as single crystals of $\mathrm{KNbO}_{3}$ and $\mathrm{NaNbO}_{3}$ was proposed.

A detailed, quantitative SEM-EDS analysis using the proposed $\mathrm{KNbO}_{3}$ and $\mathrm{NaNbO}_{3}$ single crystals as standards was performed by Jenko et al. ${ }^{11}$ on KNN ceramics sintered at $1100^{\circ} \mathrm{C}$ for $2 \mathrm{~h}$ and $24 \mathrm{~h}$. The analysis revealed that the ceramics sintered for $2 \mathrm{~h}$ consisted of a matrix phase with a $(\mathrm{Na}+\mathrm{K}) / \mathrm{Nb}$ ratio close to 1 . In the ceramics sintered for $24 \mathrm{~h}$, a small number of Nb-rich secondary-phase regions were found, exhibiting a $\mathrm{Na} / \mathrm{K}$ ratio of 0.30 and a $(\mathrm{Na}+\mathrm{K}) / \mathrm{Nb}$ ratio of 0.60 (Table 2). In Fig. 2, SEM micrographs in back-scattered imaging mode (BEI) show the secondary-phase inclusions in the KNN ceramic sintered at $1100^{\circ} \mathrm{C}$ for $2 \mathrm{~h}$ and $24 \mathrm{~h}$. The increase in the amount of sodium-deficient secondary phase with the increasing sintering time was in agreement with the results of the ICP analysis. The latter confirmed a major loss of sodium in the ceramic sintered for $24 \mathrm{~h}$ compared to that sintered for $2 \mathrm{~h}^{37}$
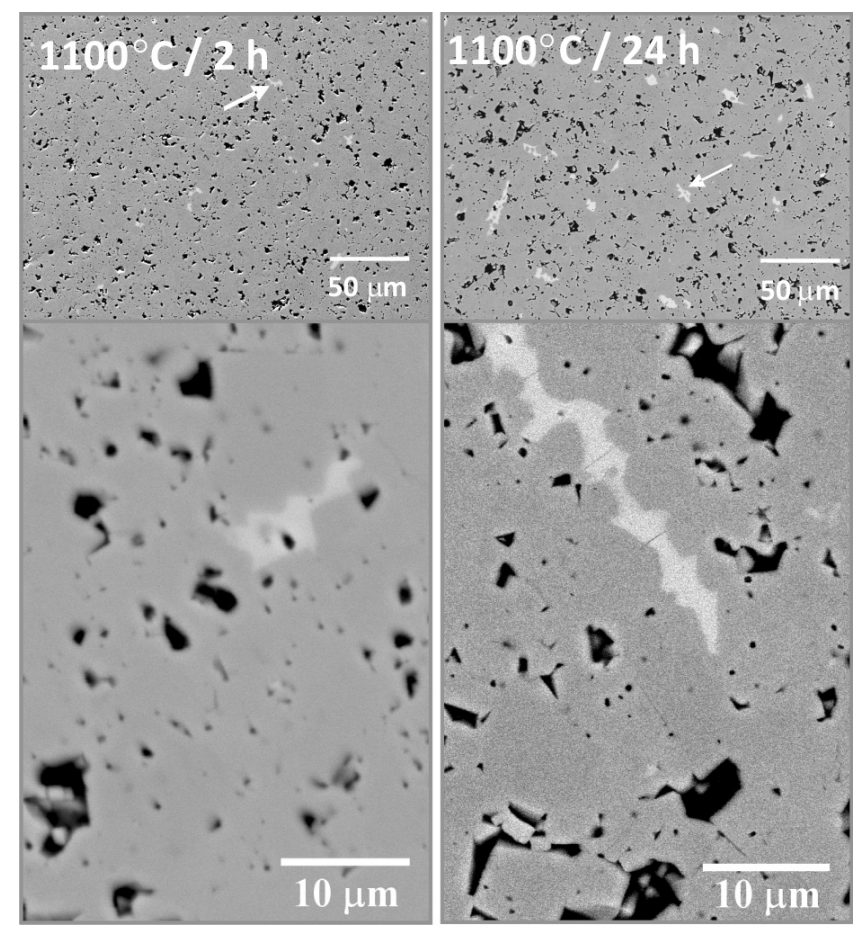

Fig. 2. SEM-BEI micrograph of the polished surface of a KNN ceramic sintered at $1100^{\circ} \mathrm{C}$ for $2 \mathrm{~h}$ and $24 \mathrm{~h}$. The arrows denote secondary-phase inclusions. ${ }^{11}$

In the latest study, a combination of SEM-WDS and standardless SEM-EDS was used by Bencan et al. for the determination of the elemental composition of a KNN single crystal prepared by solid-state single-crystal growth. ${ }^{35}$ In the case of SEM-WDS, the obtained elemental composition is very close to the nominal composition (see Table 3 ). Here, instead of common orthoclase and albite mineral standards, the authors also used $\mathrm{KNbO}_{3}$ and $\mathrm{NaNbO}_{3}$ single crystals, as proposed earlier by Samardzija et $a l .{ }^{34}$ In contrast to the SEM-WDS, the elemental composition resulting from the standardless SEM-EDS analysis is erroneous and may

Table 2. Elemental composition of KNN sintered at $1100^{\circ} \mathrm{C}$ for $2 \mathrm{~h}$ and $24 \mathrm{~h}$ determined by SEM-EDS analysis. The atomic percentages of $\mathrm{Na}, \mathrm{K}$ and $\mathrm{Nb}$ were calculated based on three anions (using a fixed valence of $1+$ and $5+$ ). The relative standard deviation is given in parentheses. The nominal composition is shown for comparison (after Jenko et al. ${ }^{11}$ ).

\begin{tabular}{|c|c|c|c|c|c|}
\hline & \multicolumn{5}{|c|}{ Atomic percent } \\
\hline & $\mathrm{Na}$ & $\mathrm{K}$ & $\mathrm{Nb}$ & $\mathrm{Na} / \mathrm{K}$ & $(\mathrm{Na}+\mathrm{K}) / \mathrm{Nb}$ \\
\hline Nominal composition & 10.0 & 10.0 & 20.0 & 1.00 & 1.00 \\
\hline $1100^{\circ} \mathrm{C} / 2 \mathrm{~h}$ matrix & $9.8 \pm 0.1(1.0 \%)$ & $10.8 \pm 0.2(1.0 \%)$ & $21.0 \pm 0.1(0.5 \%)$ & $0.91 \pm 0.02$ & $0.98 \pm 0.01$ \\
\hline $1100^{\circ} \mathrm{C} / 24 \mathrm{~h}$ matrix & $10.4 \pm 0.3(2.9)$ & $11.0 \pm 0.1(0.9 \%)$ & $20.7 \pm 0.1(0.5 \%)$ & $0.95 \pm 0.03$ & $1.03 \pm 0.01$ \\
\hline Secondary phase & $3.2 \pm 0.1(3.1 \%)$ & $10.7 \pm 0.1(0.9 \%)$ & $23.0 \pm 0.1(0.4 \%)$ & $0.30 \pm 0.01$ & $0.60 \pm 0.01$ \\
\hline
\end{tabular}


Table 3. Elemental composition in at\% of the KNN single crystal, determined by WDXS and EDXS, with a standard deviation (STDEV). The nominal composition is shown for comparison. Oxygen $\left(^{*}\right)$ is calculated from the stoichiometry (after Bencan et al. ${ }^{35}$ ).

\begin{tabular}{|c|c|c|c|c|c|}
\hline \multirow{2}{*}{ Element } & \multirow{2}{*}{$\begin{array}{c}\text { Nominal composition } \\
\text { at } \%\end{array}$} & \multicolumn{2}{|c|}{ WDXS } & \multicolumn{2}{|c|}{ EDXS } \\
\hline & & at $\%$ & STDEV & at $\%$ & STDEV \\
\hline $\mathrm{K}$ & 10 & 10.06 & 0.08 & 9.5 & 0.1 \\
\hline $\mathrm{Na}$ & 10 & 10.03 & 0.07 & 9.8 & 0.2 \\
\hline $\mathrm{Nb}$ & 20 & 19.89 & 0.10 & 20.3 & 0.3 \\
\hline $\mathrm{O}$ & 60 & 60.02 & 0.15 & $60.4^{*}$ & 0.5 \\
\hline
\end{tabular}

lead one to a wrong conclusion that a minor loss of potassium during the synthesis or a migration of the potassium ions under the electron-beam irradiation might have taken place. This was obviously not the case considering the above-mentioned SEM-WDS results (for comparison, see Table 3). According to these results, the authors proposed the KNN single crystal as an appropriate standard for the analysis of KNN ceramics. Its composition would be the closest to the KNN-based unknown materials and, consequently, the extent of the matrix corrections would also be smaller, which will result in a higher accuracy of the quantitative results.

\section{Determination of the Chemical Composition by Means of TEM}

For a detailed microstructure or chemical composition analysis on the nanoscale, TEM-based techniques are the most appropriate. The imaging spatial resolution of modern instruments is in the angstrom range, which means the structure of the ceramics can be investigated on the atomic scale. A similar analytical spatial resolution can also be obtained in the case of a TEM-EELS analysis. ${ }^{38}$ This allows detailed analytical investigations on nanopowders with grain sizes down to the tens-of-nanometer range as well as analyzing the chemical composition of ceramics starting with nanosized secondary-phase inclusions down to the segregation of impurity or dopant atoms at the grain boundaries.

The beam-specimen interaction is still an issue for TEM-EDX spectroscopy, although here the analysis volume is smaller than that in an SEM by about three orders of magnitude. The EDXS spatial resolution is defined as the smallest distance between two interaction volumes in the specimen from which independent analyses can be obtained. ${ }^{29}$ It is a function of the incident-beam diameter and beam spreading and is generally worse than the initial resolution defined by the incident electron-probe diameter.

A Monte Carlo simulated example of the interaction of $200-\mathrm{keV}$ accelerated electrons with a 200-nm-thin $\mathrm{K}_{0.5} \mathrm{Na}_{0.5} \mathrm{NbO}_{3}$ specimen is given in Fig. 3(a). In contrast to the SEM (see Fig. 1), fast TEM electrons are passing through the specimen in a narrow band. The estimated beam spreading at the exit surface of a specimen, including $90 \%$ of all the emerging electrons, is $40 \mathrm{~nm}$. The resulting spatial resolution as a function of the specimen thickness for a 200-keV accelerating voltage, a $\mathrm{K}_{0.5} \mathrm{Na}_{0.5} \mathrm{NbO}_{3}$ specimen, $1 \mathrm{~nm}$ and $10 \mathrm{~nm}$ incident beam diameters, is plotted in Fig. 3(b). This plot clearly shows that the EDXS spatial resolution is significantly improved when a finer probe is chosen and the specimen thickness is kept below $50 \mathrm{~nm}$. However, in the considered $\mathrm{K}_{0.5} \mathrm{Na}_{0.5} \mathrm{NbO}_{3}$ specimen, at thicknesses above $100 \mathrm{~nm}$, which is still appropriate for the TEM-EDXS analysis, the spatial resolution is becoming similar for both the 1 and $10 \mathrm{~nm}$ initial beam diameters. As a consequence, in thicker specimens a reasonable compromise would be to increase the beam size.

The quantitative X-ray analysis in TEM is performed by the Cliff-Lorimer ratio technique, where the ratio $C_{\mathrm{A}} / C_{\mathrm{B}}$ of the weight percent of the elements $\mathrm{A}$ and $\mathrm{B}$ is related to the spectral lines intensities ratio $I_{\mathrm{A}} / I_{\mathrm{B}}$ by a sensitivity factor $k_{\mathrm{AB}}$, also known as Cliff-Lorimer factor. ${ }^{29}$ The obtained relative errors in the measured elemental composition can be minimized when the $k$-factor is measured directly from the user defined standard. Since the $k$-factor is not a constant but depends on various TEM analytical conditions, such as the accelerating voltage, the detector efficiency, take off angle, etc., the acquisition of spectra from the 




(a)

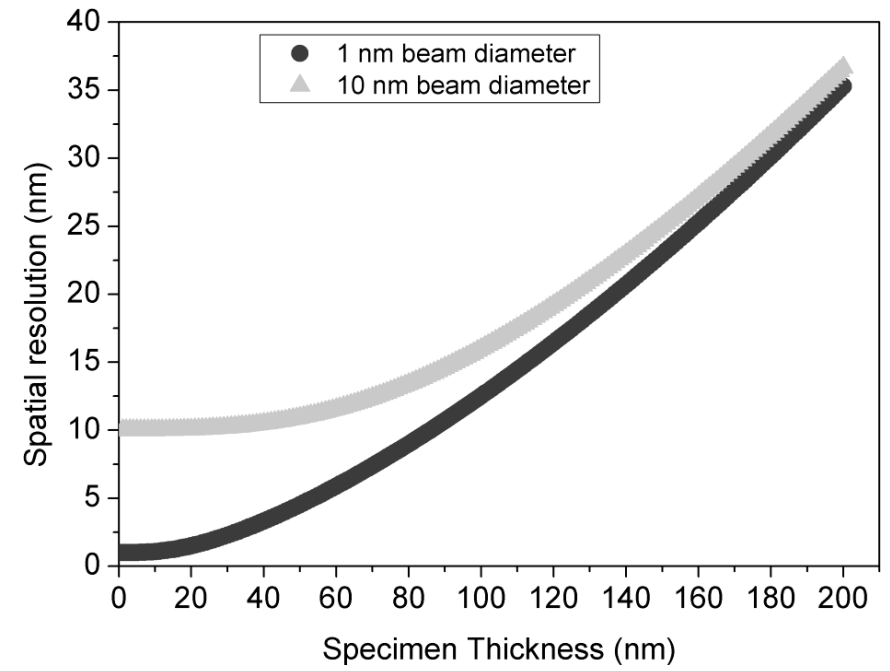

(b)

Fig. 3. (a) Monte Carlo (CASINO) simulations ${ }^{31}$ of the $3 \cdot 10^{3}$ electron trajectories through a $200-\mathrm{nm}^{-}$thick $\mathrm{K}_{0.5} \mathrm{Na}_{0.5} \mathrm{NbO}_{3}$ sample, and (b) the TEM-EDXS spatial resolution plotted against the specimen thickness. All the values are calculated assuming a TEM operating at $200 \mathrm{keV}$ with an incident-beam diameter of $1 \mathrm{~nm}$ for the Monte Carlo simulations, and 1 and $10 \mathrm{~nm}$ for the spatial resolution plot; $\mathrm{K}_{0.5} \mathrm{Na}_{0.5} \mathrm{NbO}_{3}$ is taken as the specimen.

unknown sample and from the standard has to be acquired at identical analytical conditions.

The accuracy of the quantification in TEM can be additionally reduced by statistical errors associated by the absorption, fluorescence and electron channelling. The absorption correction in this case can be done by zero-thickness extrapolation procedure. ${ }^{39}$ The fluorescence correction is usually small in most specimens and lies below the relative error of the composition determination $(\sim 3 \% \mathrm{rel})$ and, therefore, can be omitted. ${ }^{29}$ To avoid channelling effects and thus, the artificial change of the peak intensity ratios, the specimen should be tilted off the zone-axis.

Another important issue to be addressed is the thin specimen's stability under the electron irradiation in vacuum conditions. In recent publications, special attention was paid to finding the proper experimental conditions, where the initial material composition is preserved throughout the compositional data acquisition. ${ }^{40,41}$

In studies of $\mathrm{KTaO}_{3},{ }^{40}$ a standard $\mathrm{KTaO}_{3}$ specimen was tested for its compositional stability under electron irradiation prior to the compositional analysis. Plots of the normalized $\mathrm{K} / \mathrm{Ta}$ ratio determined for three different irradiation doses for both room-temperature (RT) and liquid-nitrogen-cooled (LN) measurements show similar material behavior (Figs. 4(a) and 4(b)). At the highest dose of about
$7 \mathrm{~A} / \mathrm{cm}^{2}$ the $\mathrm{K} /$ Ta ratio decreases down to about 0.8 and stabilizes at the lowest dose of about $1 \mathrm{~A} / \mathrm{cm}^{2}$. The detected loss of potassium species was found to be temperature independent, although the data for the LN lowest dose appears smoother; however, there is no significant difference compared to the RT data.

In a similar material-stability study performed on a $\mathrm{K}_{0.5} \mathrm{Na}_{0.5} \mathrm{NbO}_{3}$ standard specimen at $\mathrm{RT}$, the material showed a higher irradiation sensitivity. With $4 \mathrm{~A} / \mathrm{nm}^{2}$, i.e., half of the dose applied to the $\mathrm{KTaO}_{3}$, the $(\mathrm{K}+\mathrm{Na}) / \mathrm{Nb}$ ratio already reaches 0.75 (Fig. 5(a)). ${ }^{41}$

While EDS can give reliable compositional information provided that the specimen is stable under the electron irradiation during the whole analysis, an EELS analysis gives additional information on the bonding and valence changes in the material (for details of the method see Ref. 29). As a result, subtle changes due to the TEM beaminduced degradation as well as more detailed information on the degradation mechanism of the irradiation-sensitive ceramics can be obtained. An example of such a degradation analysis is given in Fig. 5(b). Here, the background-subtracted EEL spectra acquired from the pristine KNN, damaged $\mathrm{KNN}$ and the $\mathrm{Nb}_{2} \mathrm{O}_{5}$ standard are shown. The lefthand side part demonstrated the extended $\mathrm{Nb}-\mathrm{M}$ ionization edge, which is overlapping with the $\mathrm{K}-\mathrm{L}$ edge, while the right-hand side shows the $\mathrm{O}-\mathrm{K}$ 


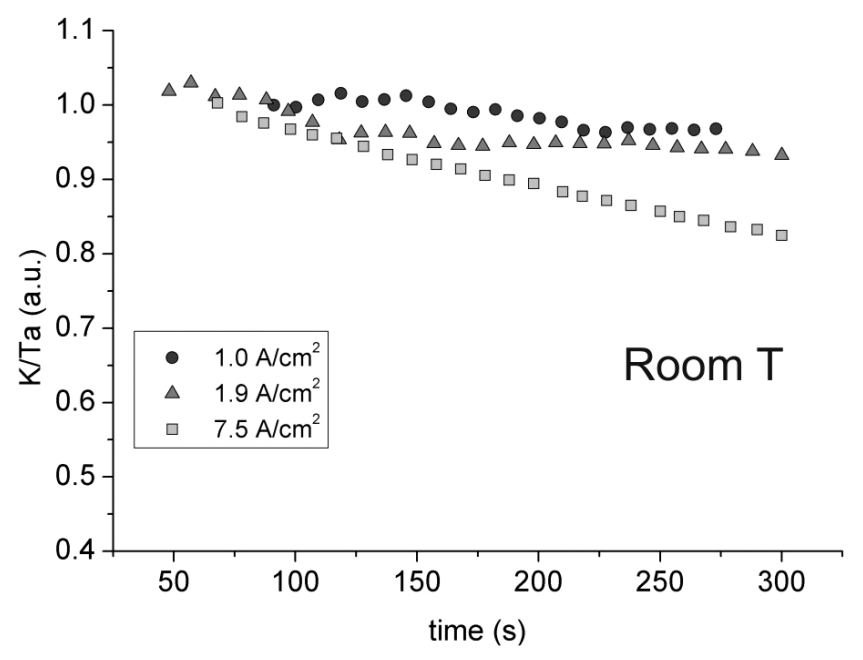

(a)



(b)

Fig. 4. Normalized K/Ta ratio versus time of irradiation with different electron doses in the TEM, obtained from a crushed $\mathrm{KTaO}_{3}$ single crystal specimen: (a) at room T, (b) cooled with LN to $-176^{\circ} \mathrm{C}$ (after Tchernychova et al. ${ }^{40}$ ).

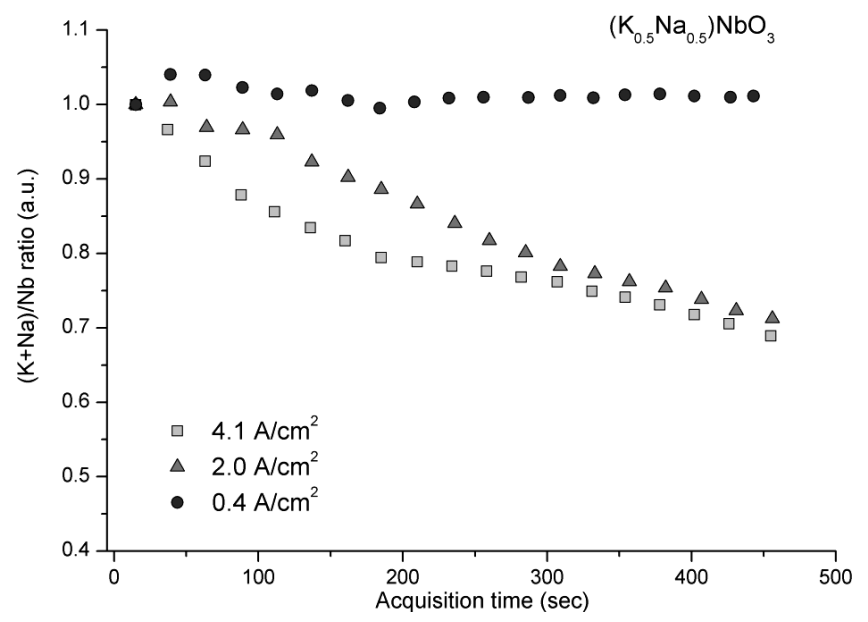

(a)

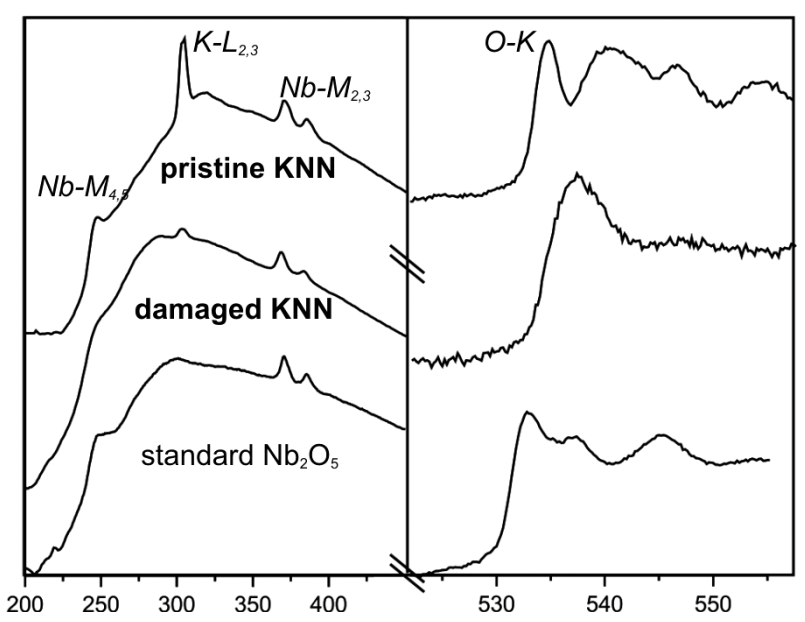

(b)

Fig. 5. (a) TEM Normalized $(\mathrm{K}+\mathrm{Na}) / \mathrm{Nb}$ ratio versus the time of irradiation with different electron doses in the TEM, obtained from a crushed $\mathrm{K}_{0.5} \mathrm{Na}_{0.5} \mathrm{NbO}_{3}$ single-crystal specimen at room $\mathrm{T}$, and (b) background-subtracted EEL spectra showing $\mathrm{K}-\mathrm{L}$, $\mathrm{Mn}-\mathrm{M}$ and $\mathrm{O}-\mathrm{K}$ ionization edges acquired from the pristine $\mathrm{KNN}$, damaged $\mathrm{KNN}$ and the $\mathrm{Nb}_{2} \mathrm{O}_{5}$ reference standard (after $\breve{S}_{\text {turm }}$ et $\left.a l .{ }^{41}\right)$.

ionization edge at $532 \mathrm{eV}$ energy loss, enlarged for clarity. The spectrum of the heavily damaged KNN acquired after $10 \mathrm{~min}$ of specimen irradiation with an electron dose of $10.4 \mathrm{~A} / \mathrm{cm}^{2}$ reveals a dramatic decrease in the $\mathrm{K}$ signal and changes to the $\mathrm{O}-\mathrm{K}$ fine structure. Moreover, the degraded fine structure of the $\mathrm{O}-\mathrm{K}$ edge is not in agreement with the $\mathrm{O}-\mathrm{K}$ fine structure of the $\mathrm{Nb}_{2} \mathrm{O}_{5}$ reference standard. Instead, a better match for the $\mathrm{O}-\mathrm{K}$ edge spectral features is provided by the $\mathrm{NbO}^{42}$ In combination with the EDS, these results indicate that in addition to the sublimation of the alkaline species, a reduction of $\mathrm{Nb}$ was also taking place. The reduction of the niobium was associated with a severe loss of oxygen during the degradation of the $\mathrm{KNN}$ in the TEM environment. ${ }^{41}$

When the proper TEM experimental conditions are determined, the material's structure and composition can be evaluated. In an analysis of nanopowders, a qualitative TEM-EDS is the perfect starting tool for probing the chemical composition. Figure 6 shows an example of a high-energy-milled 


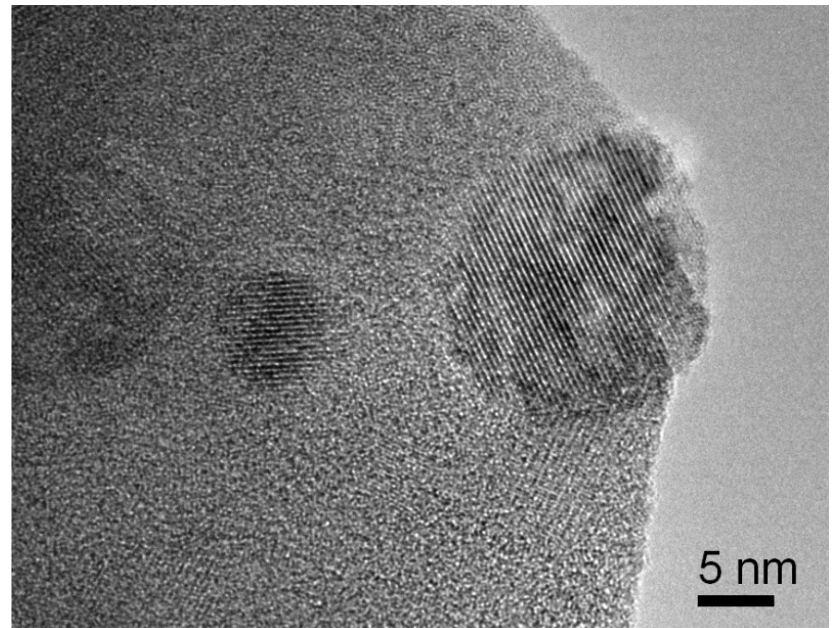

(a)



(b)

Fig. 6. (a) TEM image of the $\mathrm{K}_{2} \mathrm{CO}_{3}-\mathrm{Nb}_{2} \mathrm{O}_{5}$ mixture high-energy ball-milled for $90 \mathrm{~h}$ and (b) EDS spectra taken from nanocrystalline and amorphous regions. ${ }^{43}$

$\mathrm{K}_{2} \mathrm{CO}_{3}-\mathrm{Nb}_{2} \mathrm{O}_{5}$ mixture milled for $90 \mathrm{~h}$. The mixture consisted of the crystalline nanoparticles with sizes below $20 \mathrm{~nm}$ embedded in an amorphous matrix. In the amorphous phase, the presence of both $\mathrm{K}$ and $\mathrm{Nb}$ peaks in the TEM-EDX spectrum (Fig. 6(b)) confirmed the reaction between $\mathrm{K}_{2} \mathrm{CO}_{3}$ and $\mathrm{Nb}_{2} \mathrm{O}_{5}$ during the mechanochemical treatment. No potassium was detected in the $\mathrm{Nb}_{2} \mathrm{O}_{5}$ nanocrystallites. ${ }^{43}$

A similar analysis was employed for the study of a mechanochemically activated mixture of $\mathrm{K}_{2} \mathrm{CO}_{3}$, $\mathrm{Li}_{2} \mathrm{C}_{2} \mathrm{O}_{4}, \mathrm{Nb}_{2} \mathrm{O}_{5}$ and $\mathrm{Ta}_{2} \mathrm{O}_{5}$ powders, weighted in accordance with the $\left(\mathrm{K}_{0.485} \mathrm{Na}_{0.485} \mathrm{Li}_{0.03}\right)$ $\left(\mathrm{Nb}_{0.8} \mathrm{Ta}_{0.2}\right) \mathrm{O}_{3}$ (KNLNT) nominal composition. ${ }^{44}$ The TEM-EDS analysis of a 20-h-activated mixture consisting of nanocrystallites embedded into the amorphous matrix showed that the nanocrystalline fraction of the mixture was corresponding to either $\mathrm{Nb}_{2} \mathrm{O}_{5}$ or $\mathrm{Ta}_{2} \mathrm{O}_{5}$, while the TEM-ED spectra taken from the amorphous matrix contained additional $\mathrm{K}$ and $\mathrm{Na}$ peaks. The results were found to be in accordance with XRD measurements, where no new crystalline phases were detected. This confirmed the amorphous nature of the carbonato complex, the formation of which was found to play an essential role in the synthesis of homogenous KNLNT ceramics.

A quantitative TEM-EDS analysis of the powder gives much more precise information on the powder's chemical composition and the possible sources of compositional inhomogenieties in a subsequently processed ceramic. The importance of a detailed insight into the nanoscale composition can be illustrated for the example of a $\mathrm{KTaO}_{3}$ ceramic prepared from mechanochemically activated precursor powder. Prior to the TEM analysis, the authors performed the irradiation-stability tests described earlier in the article. This meant the possible artifacts attributed to the irradiation damage could be excluded. The XRD analysis performed on the powder after $4 \mathrm{~h}$ of calcination at $800^{\circ} \mathrm{C}$ showed the presence of only the perovskite phase. An identical result was observed for the ceramic that was hot pressed for $2 \mathrm{~h}$ at $1250^{\circ} \mathrm{C}$ and $25 \mathrm{MPa} .{ }^{40}$ However, during the conventional TEM analysis of the powder, the incomplete perovskite crystallization along with the existence of nanoparticles attached to the powder particles were discovered (Fig. 7(a)). The chemical composition of the powder shown in Fig. 7(b) revealed the presence of both $\mathrm{K}$ - and Ta-rich fractions. Nevertheless, the majority of the well-crystallized particles had a perovskite composition with a slight shift to the K-rich side due to the presence of the remaining $\mathrm{K}$-rich amorphous phase.

The hot-pressed ceramic, in its turn, exhibited an abnormal grain-growth phenomenon (Fig. 7(c)) accompanied by the compositional inhomogeneity (Fig. 7(d)). The majority of the matrix grains showed the perovskite composition with a slight 


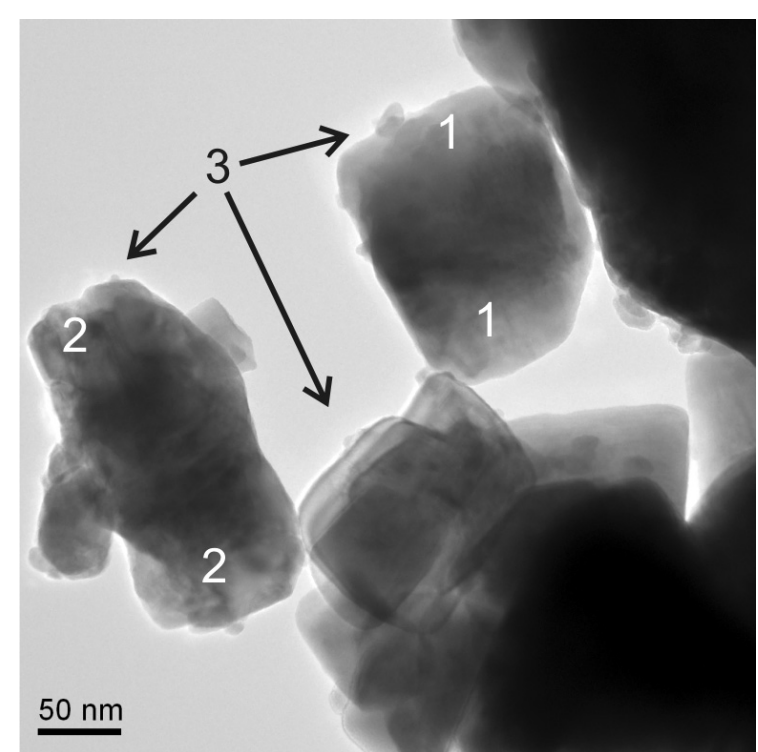

(a)



(c)

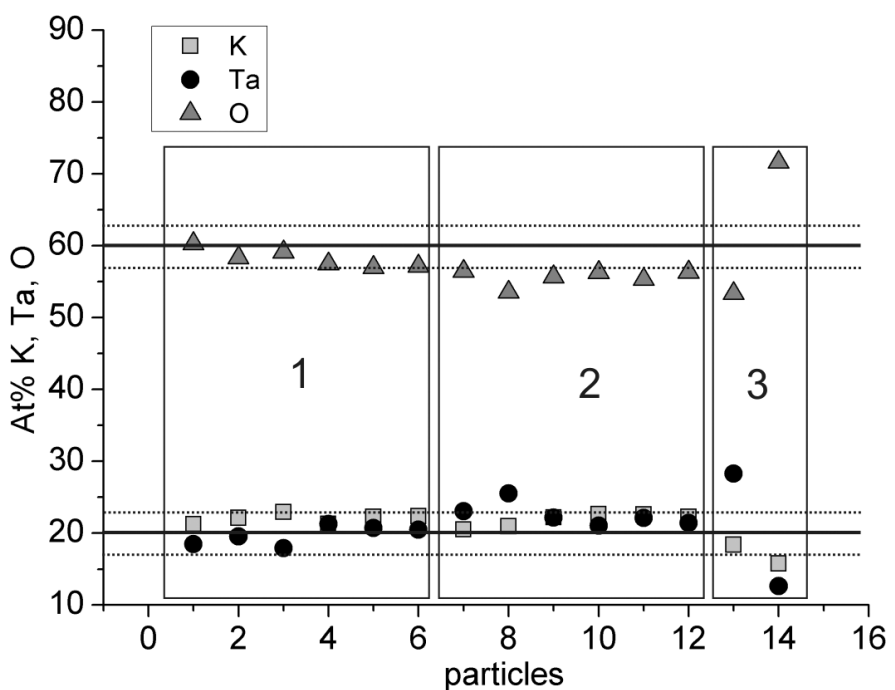

(b)

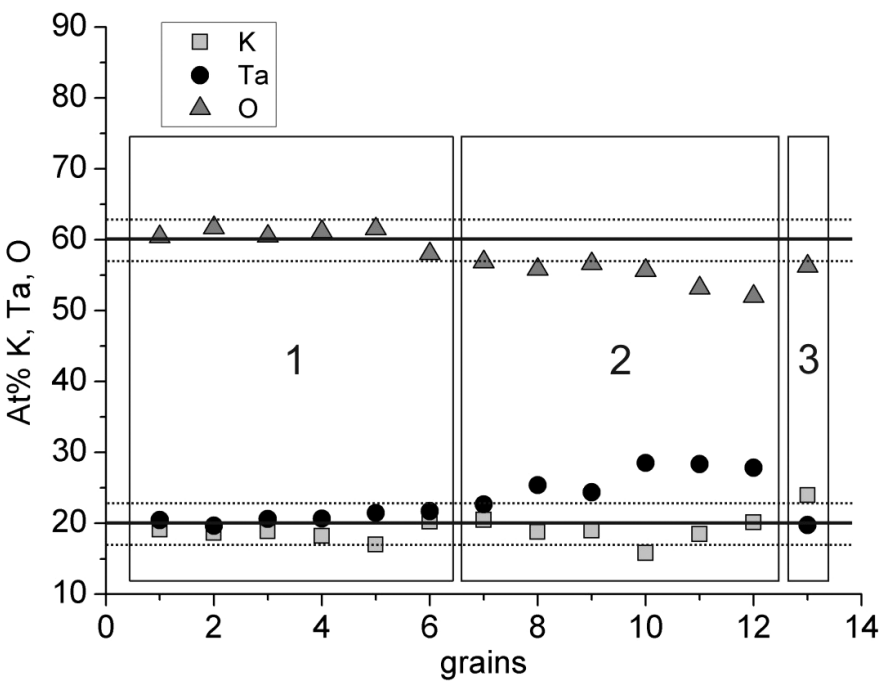

(d)

Fig. 7. (a) TEM micrograph of $\mathrm{KTaO}_{3}$ powder. The numbers represent the area from which (b) the powder's complete composition was derived. Area (1) represents well-crystallized cubic-shaped particles, area (2) represents particles with disturbed edges, area (3) represents small, poorly crystalline or amorphous particles attached to large ones. (c) TEM micrograph of the $\mathrm{KTaO}_{3}$ hot-pressed ceramic with the numbers corresponding to the areas in the (d) composition plot. Area (1) corresponds to the areas of the matrix grains, area (2) corresponds to the Ta-rich matrix grains in the vicinity of large grains, and area (3) corresponds to the K-rich grains, a small amount of which were detected in the specimen. In both plots the solid line represents the nominal composition; the standard deviation of $\pm 2 \sigma$ for each element is shown in dotted lines. ${ }^{40}$

tendency for Ta-rich grains; however, both K- and Ta-rich grains were also encountered (Fig. 7(d)). Such compositional deviations were found to be related to the chemical inhomogeneity of the precursor powder.

Such a detailed compositional analysis exposed the problems stemming from the synthesis route, which led to the large compositional inhomogeneity in the final ceramic. The addition of one more calcination step for the mechanochemically activated powder prior to hot pressing resulted in an enhanced homogeneity of the powder. Consequently, the values of the dielectric permittivity were almost doubled compared to the values obtained from the 
ceramic prepared from the single-calcined precursor powder. $^{27}$

\section{Summary}

In this review some approaches for a reliable compositional analysis of alkaline-based, lead-free perovskite ceramics by energy-dispersive X-ray spectroscopy (EDS), wavelength-dispersive X-ray spectroscopy (WDS) and electron-energy-loss spectroscopy (EELS) are addressed. Due to the presence of the volatile compounds in alkali-based ceramics, the data acquisition and interpretation have to be performed with caution. When issues such as the spatial resolution of the method, the use of appropriate standards, beam-specimen interaction, etc. are taken into account, the microscale (SEM) and nanoscale (TEM) analytical methods are perfect tools for determining and tracking an accurate chemical composition, from the precursor powder to the synthesized ceramics or single crystals.

\section{Acknowledgments}

The authors wish to acknowledge the financial support of Slovenian Research Agency (P2-105), the Ministry of Higher Education, Science and Technology of Slovenia, the $5 \mathrm{FP}$ project LEAF, the $6 \mathrm{FP}$ project IMMEDIATE and the 6FP NoE MIND.

\section{References}

1. Y. Saito, H. Takao, T. Tani, T. Nonoyama, K. Takatori, T. Homma, T. Nagaya and M. Nakamura, Nature 432, 84 (2004).

2. J. Rödel, W. Jo, K. T. P. Seifert, E. M. Anton and T. Granzow, J. Amer. Ceram. Soc. 92, 1153 (2009).

3. M. Kosec, B. Barbara, A. Benčan and T. Rojac, KNN-based piezoelectric ceramics, in Piezoelectric and Acoustic Material or Transducer Applications, Eds. A. Safari and E. K. Akdogan (New York, Springer, 2008), pp. 82-102.

4. B. Malič, A. Benčan, T. Rojac and M. Kosec, Acta Chim. Slov. 55, 719 (2008).

5. M. Kosec, B. Malič and A. Benčan, T. Rojac and J. Tellier, Functional Mat. Lett. 3, 15 (2010).

6. M. Kosec and D. Kolar, Mater. Res. Bull. 10, 335 (1975).

7. L. Egerton and D. M. Dillon, J. Am. Ceram. Soc. 42, 438 (1959).

8. E. Ringgaard and T. Wurlitzer, J. Eur. Ceram. Soc. 25, 2701 (2005).
9. P. Bomlai, P. Wichianrat, S. Muensit and S. J. Milne, J. Am. Ceram. Soc. 90, 1650 (2007).

10. B. Malič, D. Jenko, J. Holc, M. Hrovat and M. Kosec, J. Am. Ceram. Soc. 91, 1916 (2008).

11. D. Jenko, A. Benčan, B. Malič, J. Holc and M. Kosec, Microsc. Microanal. 11, 572 (2005).

12. Z. X. Chen, X. L. Zhang and L. E. Cross, J. Am. Ceram. Soc. 66, 511 (1983).

13. A. A. Axelsson, Y. Pan, M. Valant and N. Alford, J. Am. Ceram. Soc. 92, 1773 (2009).

14. J. Venkatesh, V. Sherman and N. Setter, J. Am. Ceram. Soc. 88, 3397 (2005).

15. Y. Wang, D. Damjanovic, N. Klein, E. Hollenstein and N. Setter, J. Am. Ceram. Soc. 90, 3485 (2007).

16. B. Malič, J. Bernard, A. Benčan and M. Kosec, J. Eur. Ceram. Soc. 28, 1191 (2008).

17. R. Zuo, J. Rödel, R. Chen and L. Li, J. Am. Ceram. Soc. 89, 2010 (2006).

18. A.-K. Axelsson, Y. Pan, M. Valant and N. Alford, J. Am. Ceram. Soc. 93, 800 (2010).

19. A.-K. Axelsson, M. Valant and N. Alford, J. Europ. Cer. Soc. 30, 941 (2010).

20. B. Malič, J. Bernard, J. Holc, D. Jenko and M. Kosec, J. Eur. Ceram. Soc. 25, 2707 (2005).

21. J. Tellier, B. Malic, B. Dkhil, D. Jenko and M. Kosec, Solid State Sci. 11, 320 (2009).

22. J. Attia, M. Bellaiche, P. Gemeiner, B. Dkhil and B. Malič, J. Phys. IV France 128, 55 (2005).

23. Y. Shiratori, A. Magrez and C. Pithan, J. Eur. Ceram. Soc. 25, 2075 (2005).

24. T. A. Skidmore and S. J. Milne, J. Mater. Res. 22, 2265 (2007).

25. T. Rojac, A. Benčan, H. Uršič, B. Malič and M. Kosec, J. Am. Ceram. Soc. 91, 3789 (2008).

26. N. M. Hagh, B. Jaddian and A. Safari, J. Electroceram. 18, 339 (2007).

27. S. Glinšek, B. Malič, T. Rojac, C. Filip, B. Budič and M. Kosec, J. Am. Ceram. Soc. (2011). DOI:10.1111/j.1551-2916.2010.04254.x.

28. J. Goldstein, C. E. Lyman, D. E. Newbury, E. Lifshin, P. Echlin, L. Sawyer, D. C. Joy and J. R. Michael, Scanning Electron Microscopy and $X$-ray Microanalysis, 3rd edn. (Kluwer Academic and Plenum Publishers, New York, 2003).

29. D. Williams and C. B. Carter, Transmission Electron Microscopy: A Textbook for Material Science, 1st edn. (Springer, 2009), pp. 664-667.

30. J. Acker, H. Kungl and M. Hoffmann, J. Am. Ceram. Soc. 93, 1270 (2010).

31. D. Drouin, A. Réal Couture, D. Joly, X. Tastet, V. Aimez and R. Gauvin, Scanning 29, 92 (2007).

32. Y. Zhen and J. F. Li, J. Am. Ceram. Soc. 89, 3669 (2006).

33. Y. Wang, D. Damjanovic, N. Klein and N. Setter, J. Am. Ceram. Soc. 91, 1962 (2008). 
34. Z. Samardžija, S. Bernik, R. Marinenko, B. Malič and Miran Čeh, Microchim. Acta 145, 203 (2004).

35. A. Benčan, E. Tchernychova, M. Godec, J. Fisher and M. Kosec, Microsc. Microanal. 15, 435 (2009).

36. K. Jurek, V. Hulinsky, O. Gedeon, Mikrochim. Acta Suppl. 13, 339 (1996).

37. D. Jenko, Synthesis of (K,Na)NbO ceramics, Ph.D. Thesis, University of Ljubljana, Ljubljana (2006).

38. R. F. Egerton, Electron Energy Loss Spectroscopy, 2nd edn. (Plenum Press, New York, 1996).

39. Z. Horita, T. Sano and M. Nemoto, J. Microsc. 143, 215 (1986).
40. E. Tchernychova, S. Glinšek, B. Malič and M. Kosec, J. Am. Ceram. Soc. (2010), DOI:10.1111/j.15512916.2010.04288.x.

41. S. Šturm, A. Benčan, M. A. Gülgün, B. Malič and M. Kosec, to appear in J. Am. Ceram. Soc. (2010).

42. D. Bach, R. Schneider, D. Gerthsen, J. Verbeeck and W. Sigle, Microsc. Microanal. 15, 505 (2009).

43. T. Rojac, M. Kosec, M. Polomska, B. Hilczer, P. Šegedin and A. Benčan, J. Eur. Ceram. Soc. 29, 2999 (2009).

44. T. Rojac, A. Benčan and M. Kosec, J. Am. Ceram. Soc. 39, 1619 (2010). 